\title{
Assessment of Water Quality for Irrigation Purpose: A Case Study of Bassi and Chaksu Tehsils, Jaipur District, Rajasthan, India.
}

\section{Evaluación de la calidad del agua para fines de riego: un estudio de caso de Bassi y Chaksu Tehsils, distrito de Jaipur, Rajasthan, India.}

\author{
Dr. Arjun Lal Meena ${ }^{1}$ and Priyanka Bisht ${ }^{2}$
}

1- Assistant Professor, Department of Geography, Jai Narain Vyas University, Jodhpur, Rajasthan, India. Email: arjunjnvu@gmail.com

2- Research Scholar, Department of Geography, Jai Narain Vyas University, Jodhpur, Rajasthan, India. Email: priyankabisht2710@gmail.com

\section{ABSTRACT}

Quality of Groundwater has assessed for irrigation purpose to get the suitability of water. Water samples has analysed by employing different parameters: Electrical Conductivity, Sodium Absorption Ratio (SAR), Soluble Sodium Percentage (SSP), Residual Sodium Carbonate (RSC), Kelly's Ratio, Potential Salinity and Corrosive Ratio. Suitability of Water for irrigation has presented by the diagram based on the combination of Electrical Conductivity and Sodium Absorption Ratio suggested by United States Department of Agriculture (USDA). Livelihood of the study area depends on the Agriculture and allied activities so it becomes more important to analyse the quality of water for irrigation.

Keywords: Irrigation, Electrical Conductivity, Sodium Absorption Ratio, Kelly's Ratio, Soluble Sodium Percentage.

\section{RESUMEN}

La calidad del agua subterránea se ha evaluado con fines de riego para obtener la idoneidad del agua. Las muestras de agua se analizaron empleando diferentes parámetros: conductividad eléctrica, relación de absorción de sodio (SAR), porcentaje de sodio soluble (SSP), carbonato de sodio residual (RSC), relación de Kelly, salinidad potencial y relación corrosiva. La idoneidad del agua para riego ha sido presentada por el diagrama basado en la combinación de conductividad eléctrica y relación de absorción de sodio sugerida por el Departamento de Agricultura de los Estados Unidos (USDA). El sustento del área de estudio depende de la agricultura y las actividades aliadas, por lo que se vuelve más importante analizar la calidad del agua para riego.

Palabras clave: Riego, Conductividad eléctrica, Relación de absorción de sodio, Relación de Kelly, Porcentaje de sodio soluble. 


\section{INTRODUCTION}

Water is one of the most essential substance on the earth which is necessary to maintain the life on the earth (Meena, et.al, 2020). It is transparent and colourless at its purest form. On Earth, Highest Portion (96.5\%) of Available water on planet's crust is in seas and oceans, $1.7 \%$ is trapped in caps of Antarctica and Greenland and $0.001 \%$ in atmosphere as Vapour (CGWB Faridabad, 2018). Water quality is used to express the suitability of water in various processes. Water quality is affected by a wide range of natural processes and anthropogenic activities. Natural processes are related to geological, Hydrological and Rainfall while anthropogenic processes are agricultural, industrial and urbanization (M. Meybeck, et.al,1996).

There are various minerals or ions present in the water which influences the quality of water and make it either suitable or unsuitable for irrigation. In this way, Presences of these minerals in irrigation water influence the agriculture production and even affect the soil texture, quality and properties. Water constitutes several minerals e.g. Calcium, Sodium, Magnesium, Potassium, Sulphate etc. (Wilcox,1955).

In Jaipur District, Farmers mainly rely on ground water sources e.g. Wells, Tubewells, open-well etc. to irrigate the crops. There has been traced high concentration of minerals in underground water of District which has arose the necessity to check the quality of groundwater time to time for irrigation purpose and to determine at what extent ground water can be used with or without treatments/ amendments while using for irrigation. This study focuses on the assessment of quality of ground water of Bassi and Chaksu tehsils for irrigation purpose. Farmers utilize ground water to irrigate the crops mainly. Study is carried with the objective to assess the suitability of water quality for irrigation and its impact on the agriculture production.

\section{MATERIALS \& METHODS}

Study is carried out with the collection of water samples collected from Bassi and Chaksu tehsils, Jaipur District. 36 Water Samples have collected from 3 Villages from both tehsils. These villages were Toonga village, Manoharpura Village and Jatwara Village of Bassi Tehsil and Kadera village, Chandlai village and Ramniwaspura villages of Chaksu Tehsil.

Water Samples have collected from different ground water sources e.g. Tube-well, Open-well, well and Hand-pump etc. Water samples have analysed for irrigation purpose by taking irrigation indices e.g. Electrical Conductivity, Sodium Absorption Ratio, Soluble Sodium Percentage, Residual Sodium Carbonate, Kelly's Ratio and Potential Salinity. Combined impact of Electrical conductivity and Sodium Absorption Ratio (SAR) has presented by diagram suggested by United States Department of Agriculture (USDA). In this Diagram, Water Quality is categorized into 16 classes with the different combination of Electrical Conductivity $\left(\mathrm{EC} \times 10^{\circ}\right.$ at $25^{\circ} \mathrm{C}$ in micromhos $/ \mathrm{cm}$ ) and Sodium Absorption Ratio (SAR) to analysis the suitability of water for irrigation purpose. Salinity Hazard is categorized as Low Salinity Hazard (C1), Medium Salinity Hazard (C2), High Salinity Hazard (C3) and Very High Salinity Hazard (C4) while Sodium Hazard is categorized as Low Sodium Hazard (S1), Medium Sodium Hazard (S2), High Sodium Hazard (S3) and Very High Sodium Hazard (S4). 
Sustainability, Agri, Food and Environmental Research, (ISSN: 0719-3726), 9(4), 2021: 480-490 http://dx.doi.org/10.7770/safer-VONO-art1944

Criteria of classification of Water samples have given below:

Table 1: Criteria to Classify the water samples

\begin{tabular}{lccl}
\hline \multicolumn{1}{c}{ Parameters } & Formula & Range & Water Quality \\
EC( $\mu \mathrm{mhos} / \mathrm{cm})$ & & $<250$ & Excellent/Low Salinity Hazard \\
(Richard,USDA,1954) & - & $250-750$ & Good/ Medium Salinity Hazard \\
& & $750-2250$ & Doubtful/ High Salinity Hazard \\
& $>2250$ & Unsuitable/ Very High Salinity \\
& & Hazard
\end{tabular}

Sodium Absorption

Ratio

(Richard, USDA, 1954)
$<10$

$10-18$

$18-26$

$>26$
Excellent/ Low Sodium Hazard Good/ Medium Sodium Hazard Permissible/ High Sodium Hazard Doubtful/ Very High Sodium Hazard
Soluble Sodium Percentage

(\%)

(Scofield \& Wilcox(1955), USDA)

$$
\begin{array}{ccl} 
& <20 & \text { Excellent } \\
\hline \mathrm{Na}^{+} \times 100 & 20-40 & \text { Good } \\
& 40-60 & \text { Permissible } \\
& 60-80 & \text { Doubtful } \\
& >80 & \text { Unsuitable }
\end{array}
$$

Residual Sodium Carbonate (meq./I)

(Richard,USDA,1954)

Kelly's Ratio

(Kelly, 1940 \& 1963)

$\begin{array}{lll}\frac{\mathrm{Na}^{+}}{\mathrm{Ca}^{2+}+\mathrm{Mg}^{2+}} & <1 & \text { Safe/Suitable } \\ & >1 & \text { Unsafe/Unsuitable }\end{array}$

\section{RESULTS AND DISCUSSION}

Quality of Water Samples have presented in following manner:

Electrical Conductivity- High EC in water lead to psychological drought which make less availability of water to plants even soil seems wet. This Psychological drought reduces to yield. Water Samples have exhibited high EC which show high concentration of salts in water (Wilcox,L.V.1955). 52.78\% samples have found unsuitable for irrigation, $44.44 \%$ in Doubtful category and $2.78 \%$ in good Category. On the basis of EC, $77.78 \%$ samples of Chaksu have reported unsuitable while it was $27.78 \%$ in Bassi Tehsil. 


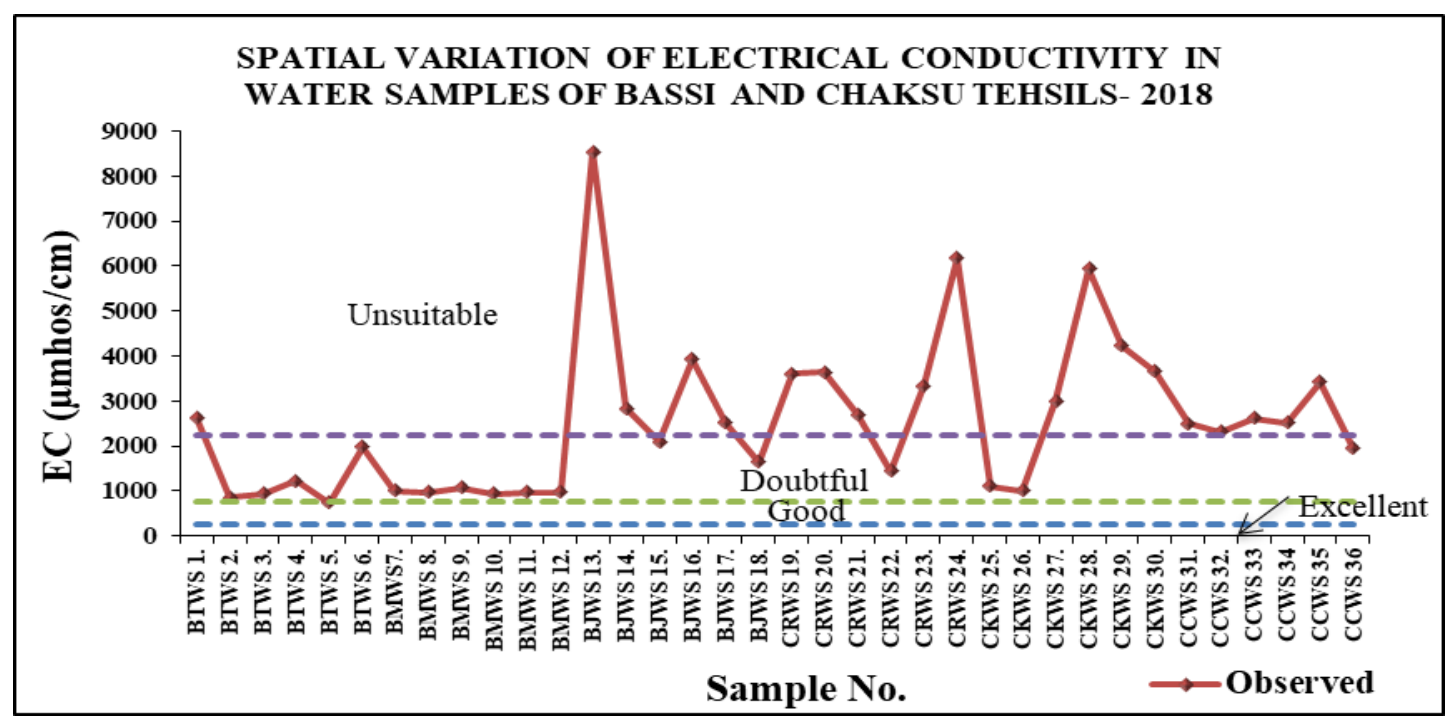

Source: (Meena, et. al, 2020)

Figure 1: Categorization of Water samples of Bassi and Chaksu Tehsils Based on Electrical Conductivity- 2018

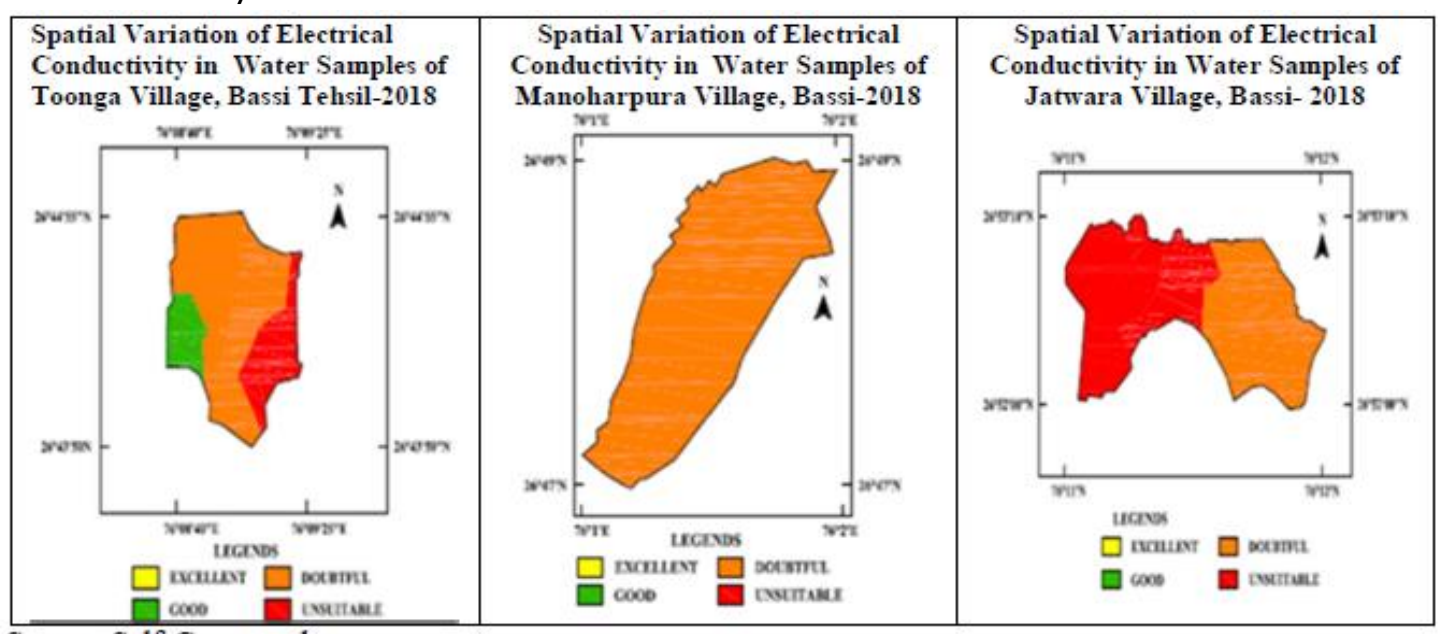

Source: Self-Composed

Figure 2: Spatial Variation of Electrical Conductivity in Water Samples of Villages of Bassi Tehsil- 2018.

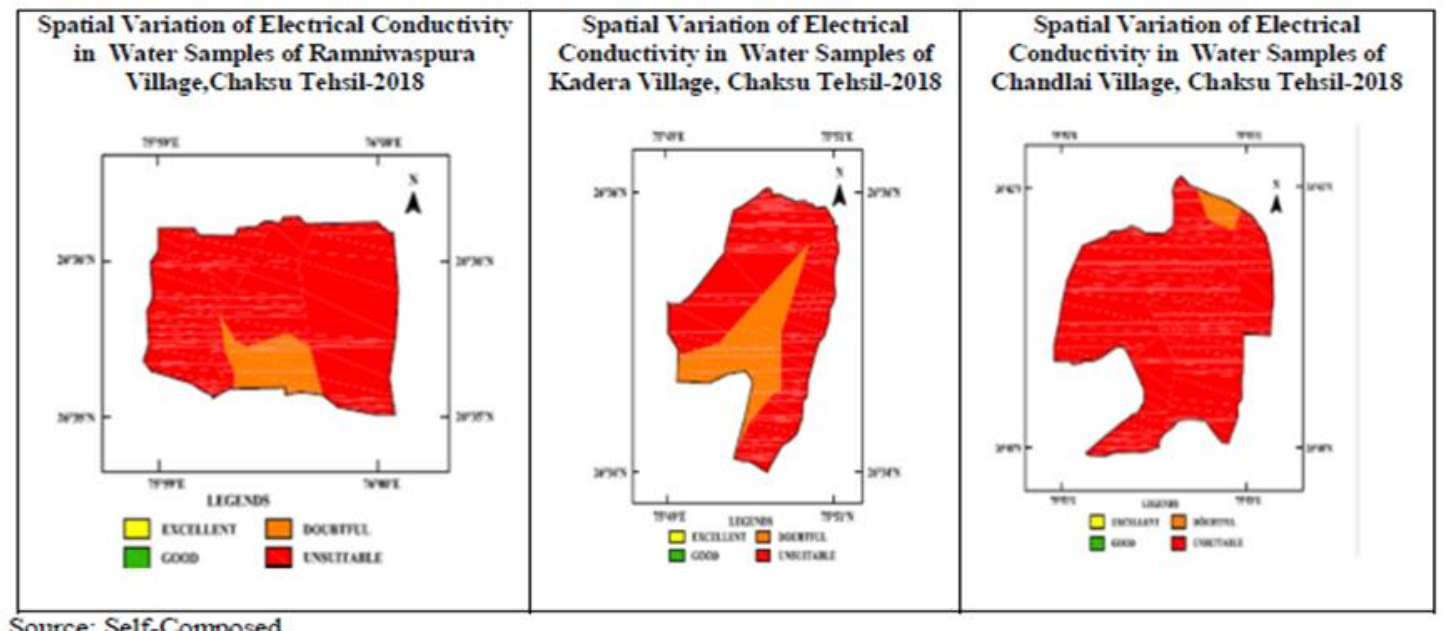

Figure 3: Spatial Variation of Electrical Conductivity in Water Samples of Villages of Chaksu Tehsil- 2018 
Sodium Absorption Ratio (SAR) - Sodium Absorption Ratio denotes the ability of sodium ions to replace the Calcium and Magnesium ions from soil. This rearranges the soil particles and reduces the pore size which makes less infiltration to water to reach the roots of plants (Pick, Tom.2011). Most of Samples have found excellent on the basis of Sodium Absorption Ratio. $66.67 \%$ samples have found excellent, $30.55 \%$ in good category and $2.78 \%$ in permissible category.

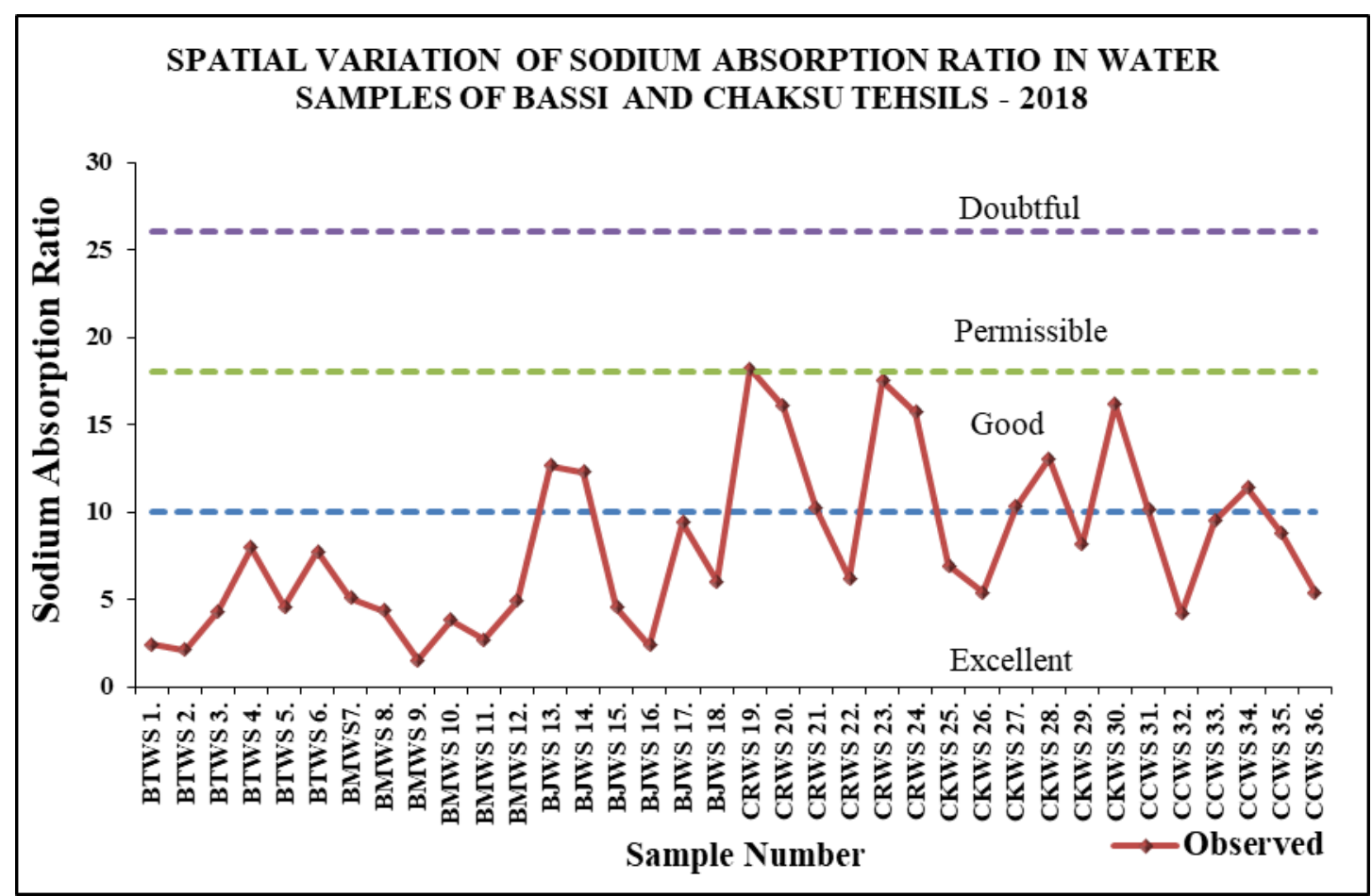

Figure 4: Spatial Variation of Sodium Absorption Ratio in Water Samples of Villages of Bassi and Chaksu tehsils- 2018

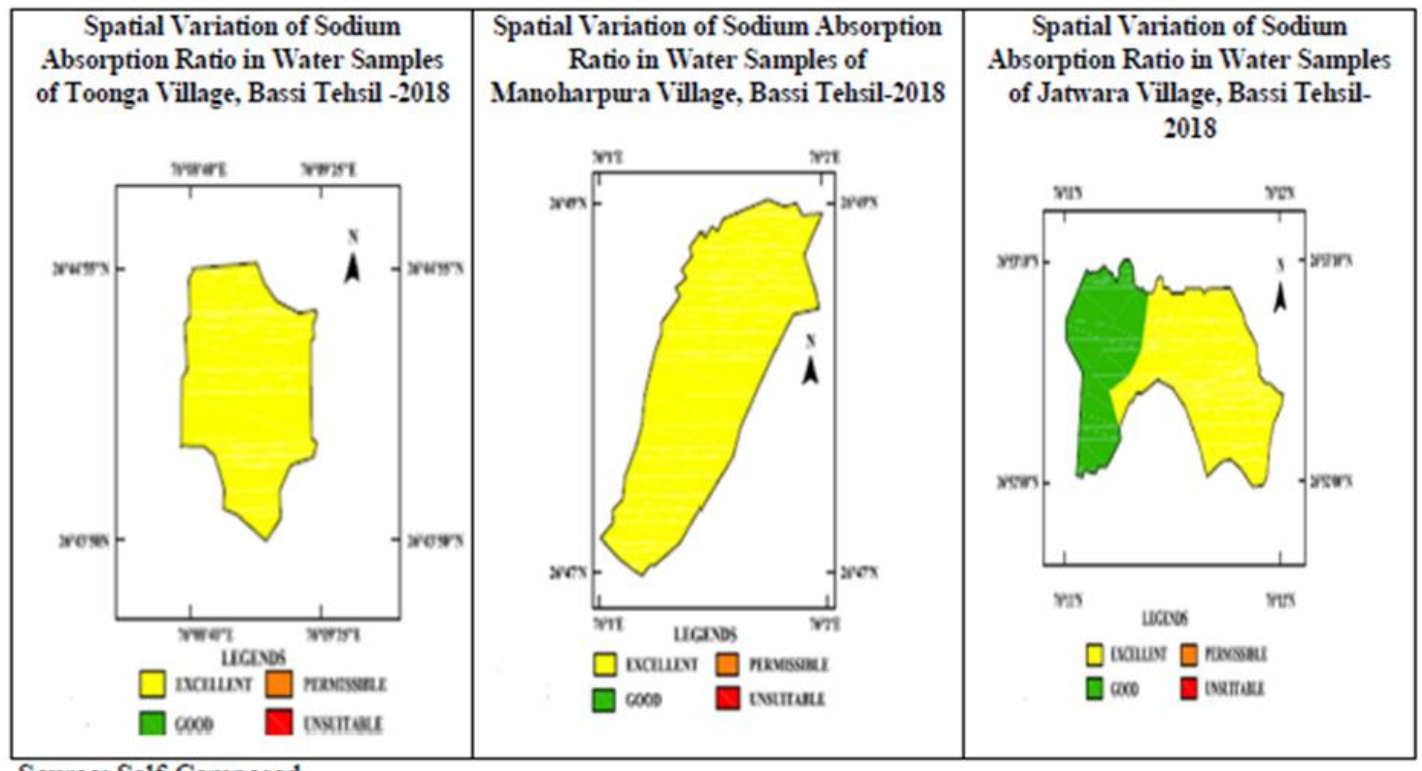

Source: Self-Composed

Figure 5: Spatial Variation of Sodium Absorption Ratio in Water Samples of Villages of Bassi Tehsil- 2018 


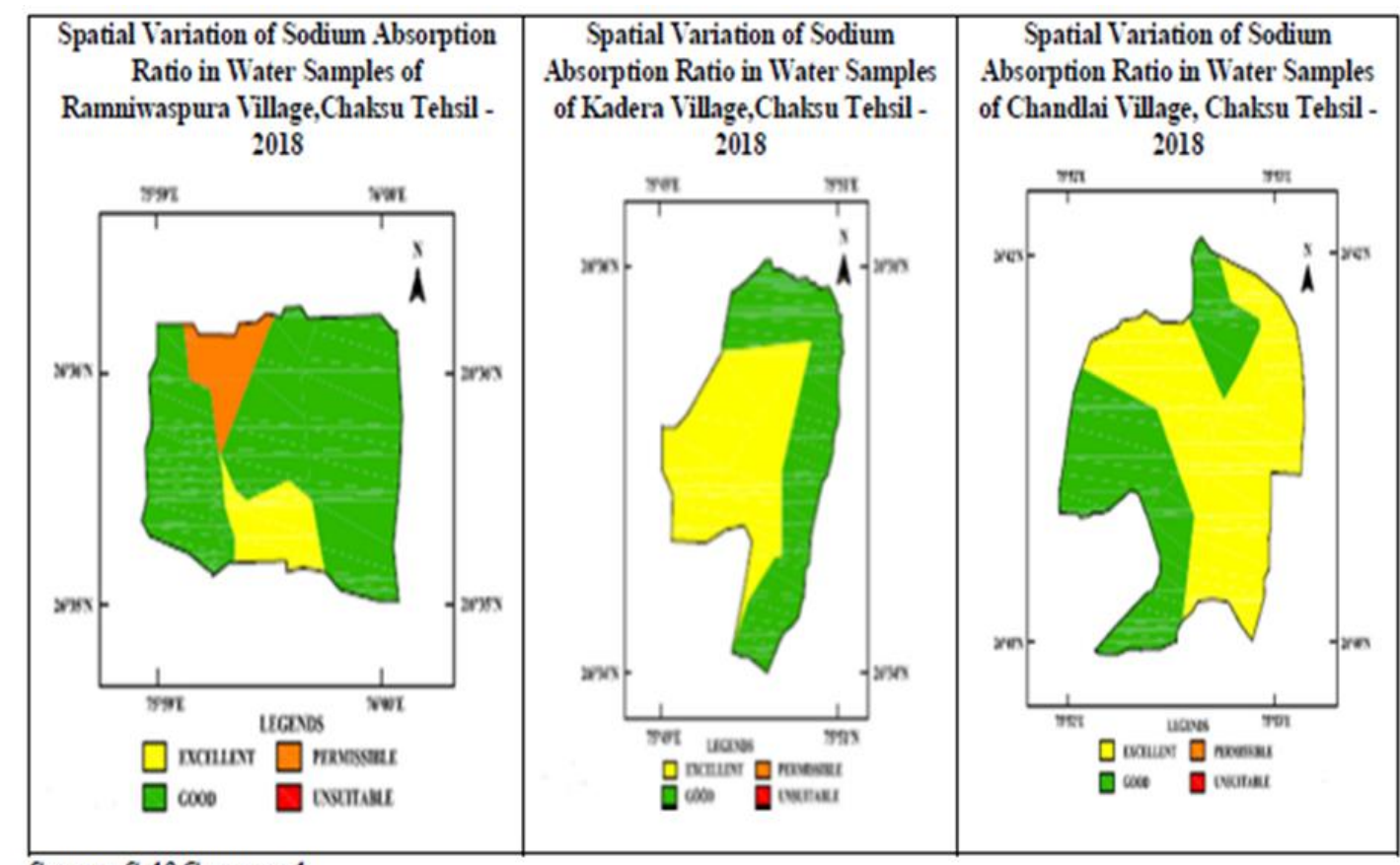

Source: Self-Composed

Figure 6: Spatial Variation of Sodium Absorption Ratio in Water Samples of Villages of Chaksu Tehsil - 2018

Soluble Sodium Percentage (SSP) - Soluble Sodium Percentage show the sodium hazard in water and make it unfit for irrigation (Wilcox, L.V. 1955). Only 5.56\% samples have traced unsuitable for irrigation while $58.33 \%$ have found doubtful. Only $22.22 \%$ samples have considered permissible and $13.89 \%$ in Good Category.

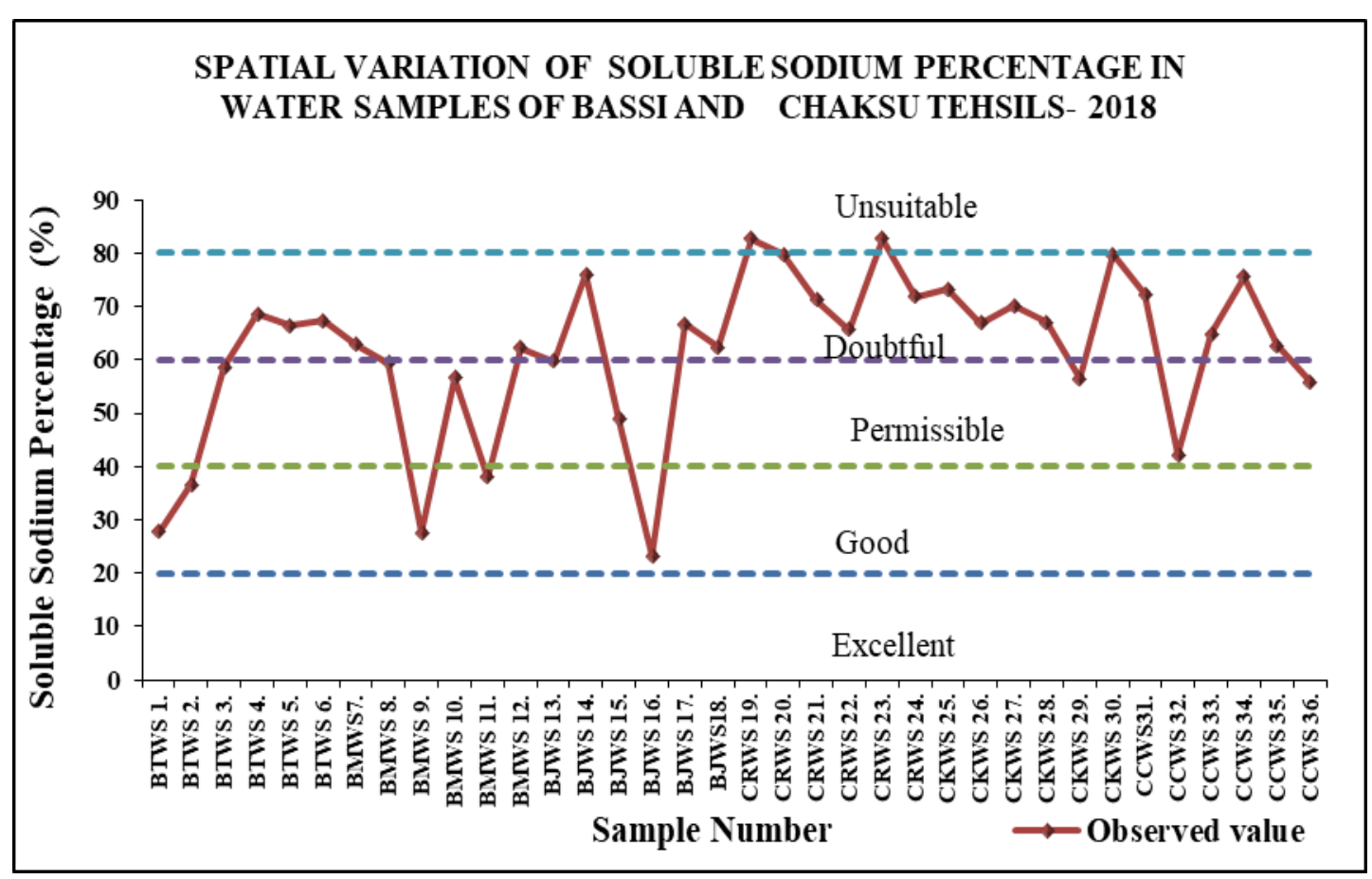

Figure 7: Spatial Variation of Soluble Sodium Percentage in Water Samples of Bassi and Chaksu Tehsils- 2018 


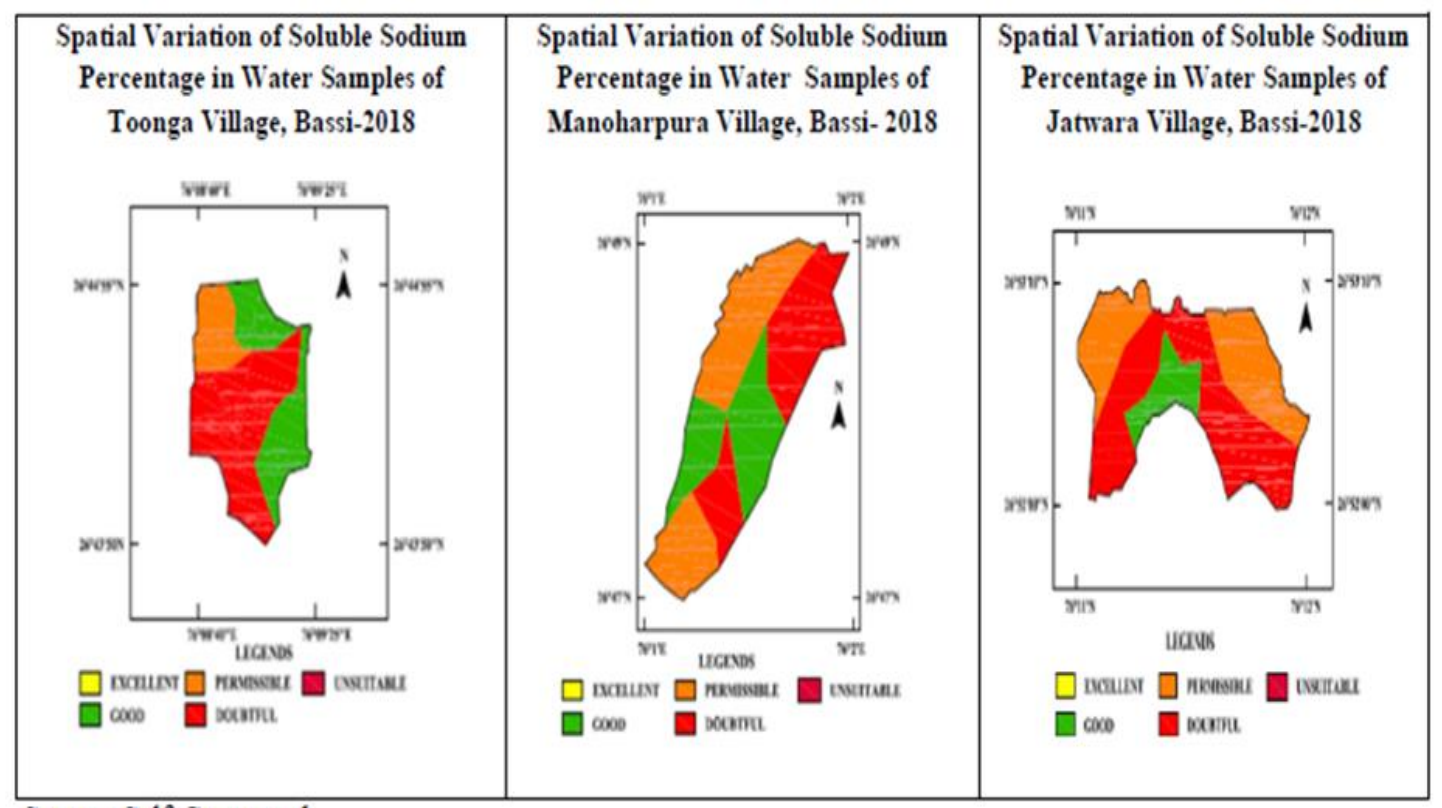

Source: Self-Composed

Figure 8: Spatial Variation of Soluble Sodium Percentage in Water Samples of Village of Bassi Tehsil- 2018

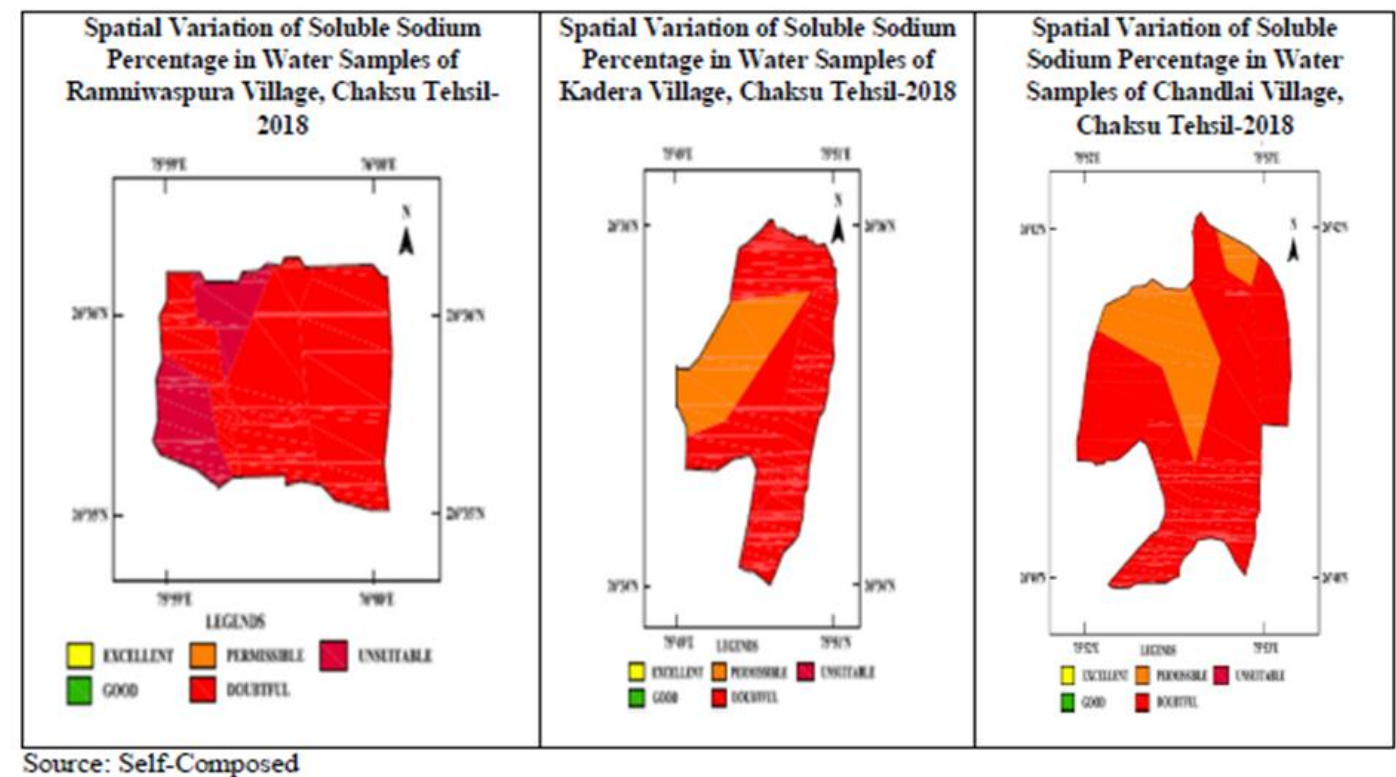

Figure 9: Spatial Variation of Soluble Sodium Percentage in Water Samples of Villages of Chaksu tehsil- 2018

Residual Sodium Carbonate (RSC) - This show the dominance of Carbonate and BiCarbonate over the Concentration of Calcium and Magnesium. High Concentration of Carbonates precipitates the Calcium and Magnesium which give black stain on drying (Richard, 1954). Most of Samples have found unsuitable for irrigation. $61.11 \%$ samples have found unsuitable while $2.78 \%$ samples have found moderate and $36.11 \%$ samples have found safe for irrigation purpose. 


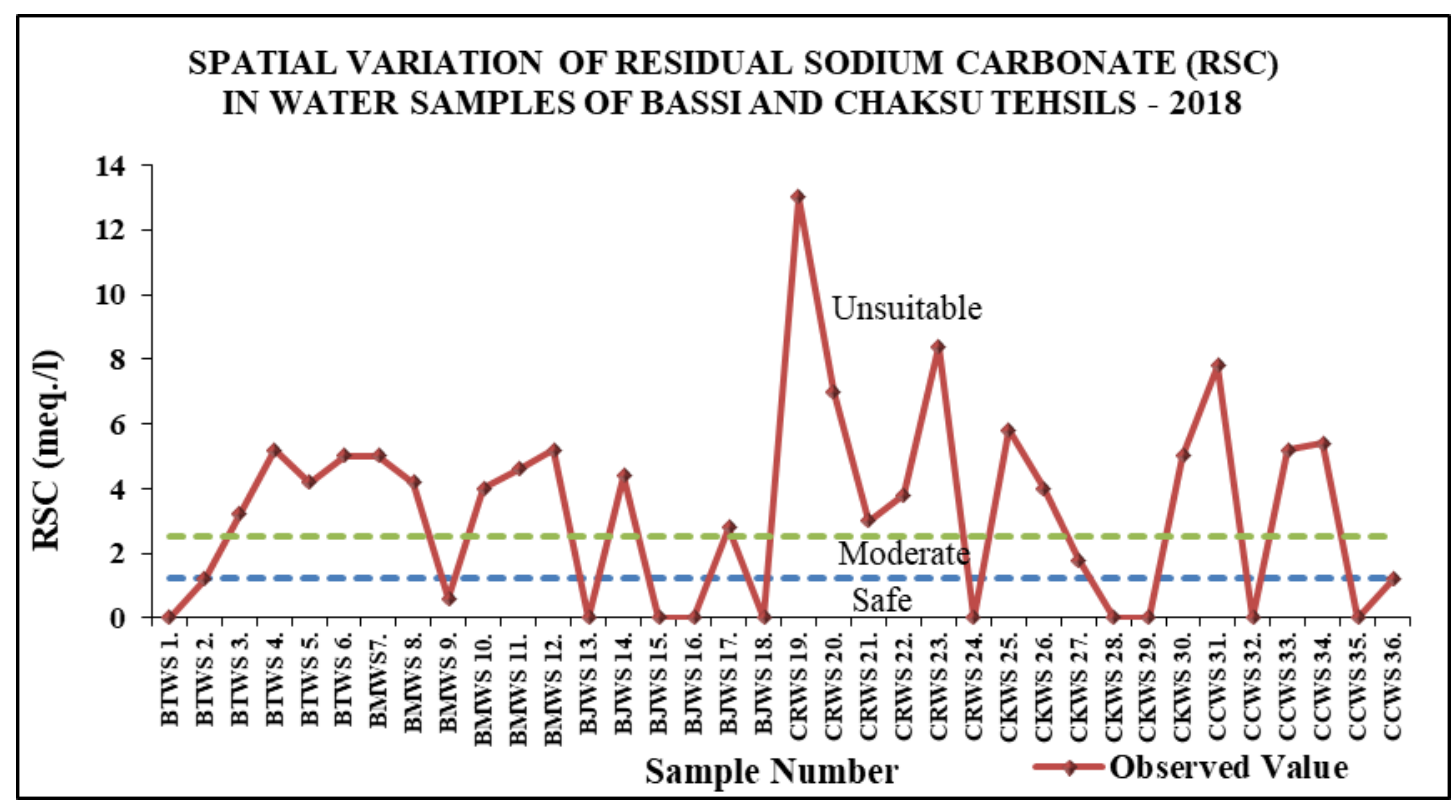

Figure 10: Spatial Variation of Residual Sodium Carbonate in Water Samples of Bassi and Chaksu Tehsils- 2018

Kelly's Ratio - Kelly's Ratio is the ratio of sodium to Calcium and Magnesium (Rawat et.al, 2018). More than half of samples have traced unsuitable for irrigation. $80.56 \%$ samples have found unsuitable and rest have considered suitable. $66.67 \%$ samples of Bassi have considered unsafe and $94.44 \%$ samples of Chaksu have considered unsafe.

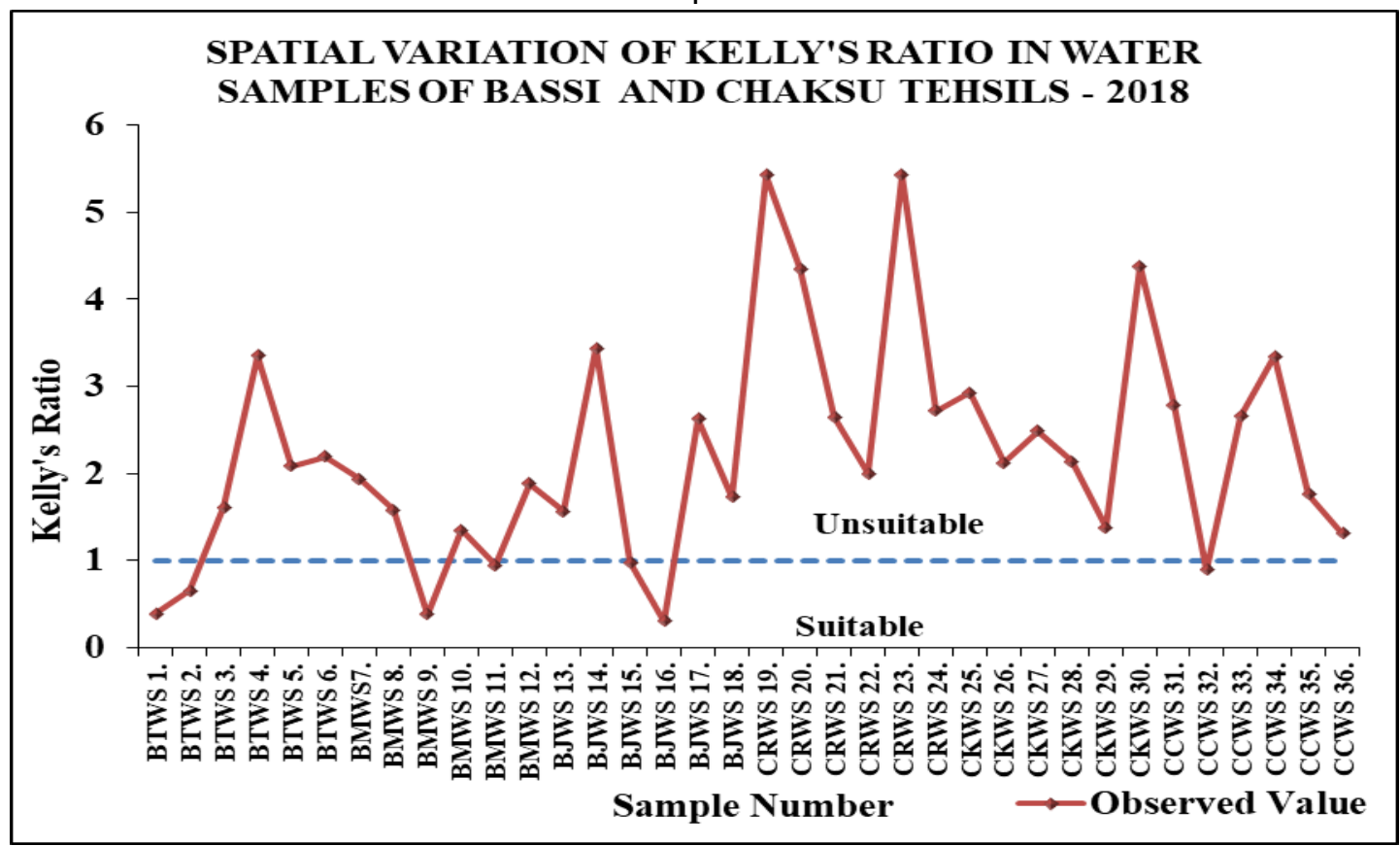

Figure 11: Spatial Variation of Kelly's Ratio in Water Samples of Bassi and Chaksu Tehsils- 2018

Potential Salinity - This indicate the suitability of water on the basis of concentration of insoluble salt (Rawat et.al, 2018). Water samples of Manoharpura village have shown low potential salinity from irrigation point of view while water samples from Jatwara village of Bassi tehsil have exhibited high value of potential salinity even it has 
reached to 71.80 meq./I in some samples. This has shown that two villages of Bassi tehsil have retained opposite water quality. Most Water samples of Chaksu tehsil have exhibited very high potential salinity which has shown high concentration of insoluble salt (Bisht, Priyanka. 2020).

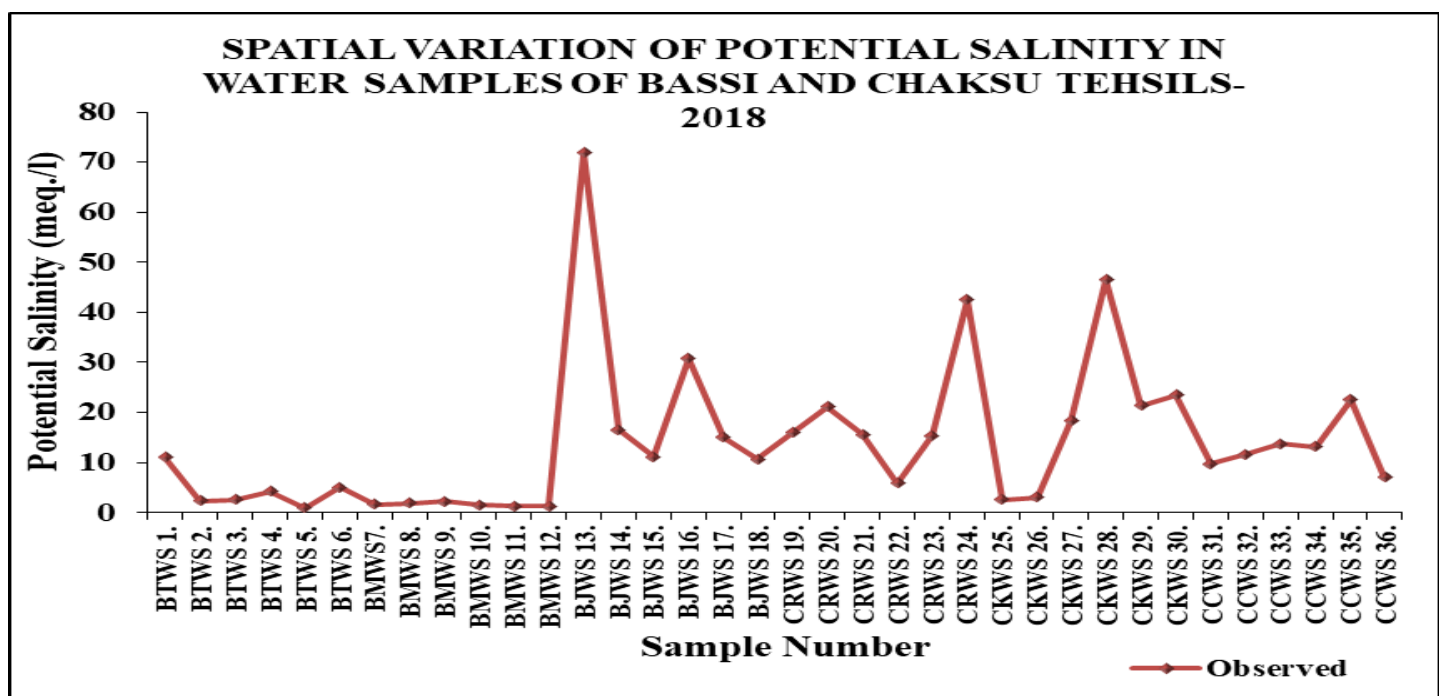

Figure 12: Spatial Variation of Potential Salinity in Water Samples of Bassi and Chaksu tehsils- 2018

Classification of Water Based on EC and SAR- Based on the combination of Electrical Conductivity and Sodium Absorption Ratio (Suggested by The United States Department of Agriculture), Water samples fall in 07 classes. $25 \%$ samples have found in each class viz. C4-S3 and C3-S1 while $19.44 \%$ samples have found in each class viz. C4-S4 and C3S2. $2.78 \%$ samples have found to lie in C2-S1 class and C4-S2 and $5.56 \%$ in class C4S1 (Table 2). Most of Samples have shown high Salinity and Sodium Hazard which have shown that water should be apply with some treatments. Only one sample have exhibited Medium salinity and low Sodium Hazard which belongs to Toonga village, Bassi While Very High Salinity and Sodium Hazard (C4-S4) have traced in 07 samples out of which 01 samples from Bassi and Rest from Chaksu (in fig 13, two samples point are overlapped as the value are almost same)( Bisht, Priyanka. 2020).

Table 2: Classification Based on The Combination of EC and SAR in Water samples of Bassi and Chaksu tehsils- 2018

\begin{tabular}{llc}
\hline Water Classes & \multicolumn{1}{c}{ Water Type } & Percentage of Samples \\
C2-S1 & Medium Salinity and Low Sodium Hazard & 2.78 \\
C3-S2 & High Salinity and Medium Sodium Hazard & 19.44 \\
C3-S1 & High Salinity and Low Sodium Hazard & 25 \\
C4-S4 & Very High Salinity and Sodium Hazard & 19.44 \\
C4-S3 & Very High Salinity and High Sodium Hazard & 25 \\
C4-S2 & Very High Salinity and Medium Sodium & 2.78 \\
& Hazard & \\
C4-S1 & Very High Salinity and Low Sodium Hazard & 5.56 \\
Total & & 100 \\
\hline
\end{tabular}




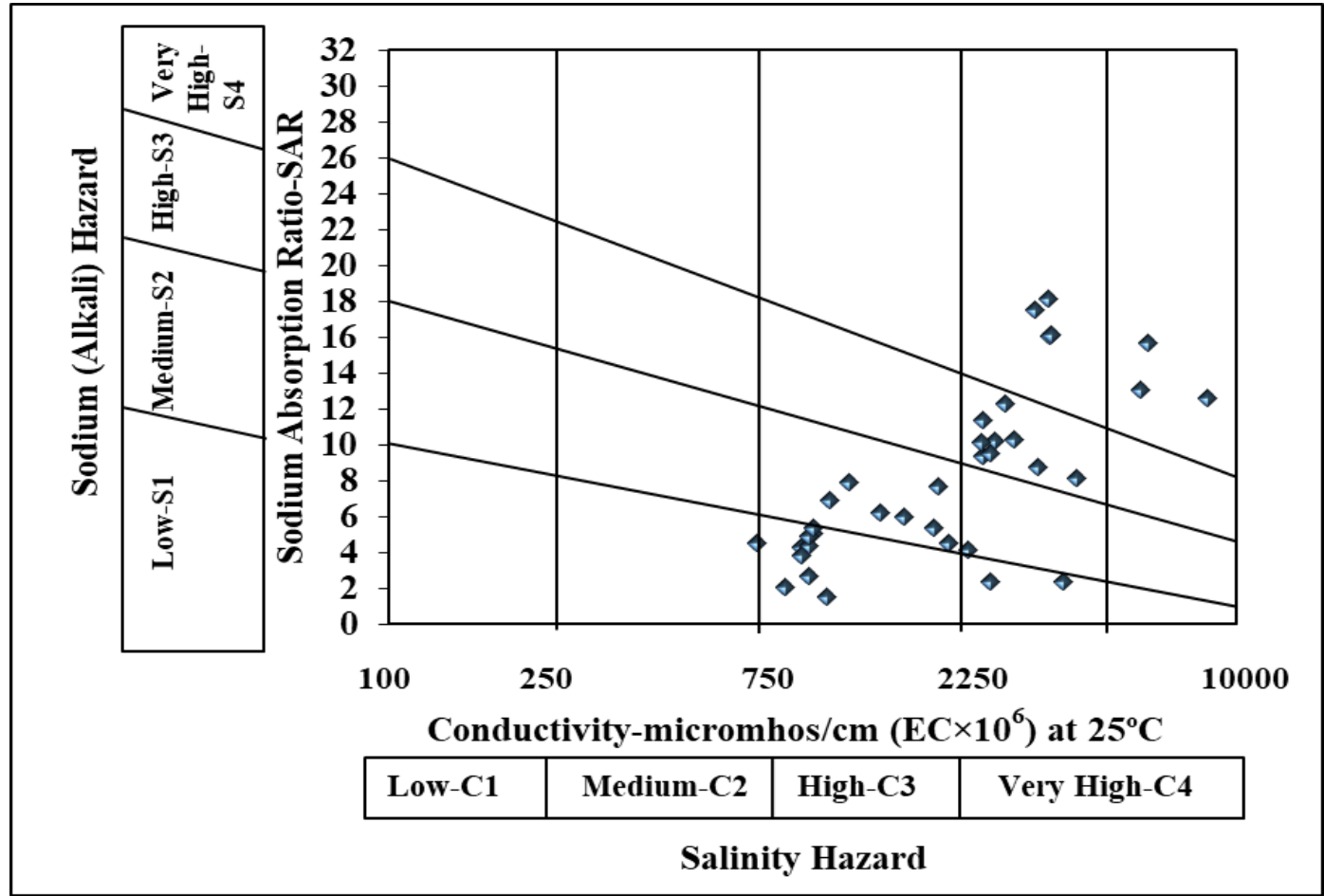

Figure 13: Classification of Water Samples of Bassi and Chaksu Tehsils based on the combination of EC and SAR (Based on USDA) -2018

It is concluded that water samples have recorded high salinity hazard but having low sodium hazard. There has traced high sodium content in samples so it could be risky to apply water on the soil and could damage the crops. On the basis of insoluble salts, Most of water samples have found injurious to apply. Water Samples collected from Chaksu have more adverse effect on soil and plant than the water samples of Bassi tehsil. Among the 6 villages, Manoharpura village, Bassi have water samples of better quality than the samples of other village. There is need to apply some amendments or treatment before the use of these types of water samples. There is needed to use leaching if these kinds of water samples are taking to apply.

\section{REFERENCES}

Bauder, T.A., Waskom, R. M., Sutherland, P.L. \& Davis, J.G.2011. Irrigation Water Quality Criteria. Colorado State University Extension. Fact sheet No. 0.506.

Bhat, Mohammad Amni., Grewal, M.S., Rajpaul, Ramprakash., Wani, Sheeraj Ahmad \& Dar, Eajaj Ahmad. Assessment of Ground Water Quality for Irrigation Purposes Using Chemical Indices. Indian Journal Of Ecology.43(2).574-579.

Bisht, Priyanka.2020. An Analytical Study of Potable Water Quality in Jaipur District, Rajasthan (A Case Study of Bassi and Chaksu Tehsils) (Unpublished Ph.D. Thesis). Department of Geography, Jai Narain Vyas University, Jodhpur, Rajasthan.

CGWB, Faridabad. 2018. Ground Water Quality in Shallow Aquifers in India. CGWB, Ministry of Water Resources RD and GR, Govt. of India.

Doneen,L.D.1954. Salinization of Soil by salts in the irrigation water. Eos, Transactions American Geographical Union.(35).6. 
Sustainability, Agri, Food and Environmental Research, (ISSN: 0719-3726), 9(4), 2021: 480-490 http://dx.doi.org/10.7770/safer-VONO-art1944

Doneen,L.D.1964. Notes on Water Quality in Agriculture, Department of Water Science and Engineering, University of California, Oakland, CA, USA

Eaton, F.M. 1950. Significance of carbonates in irrigation waters. Soil Sci. 69: 123-133

Fipps,Guy. Irrigation Water Quality Standards and Salinity Management Strategies. Texas A \& M Agrilife Extension.

Hwang, J.Y., Park, S., Kim, H.-K., Kim, M.-S., Jo, H.-J., Kim, J.-I., Lee, G.-M., Shin, I.-K. and Kim, T.-S.(2017). Hydrochemistry for the Assessment of Groundwater Quality in Korea. Journal of Agricultural Chemistry and Environment. 6, 1-29.

Kaur, Tajinder., Bhardwaj, Renu \& Arora, Saroj.2016. Assessment of Groundwater Quality For drinking and irrigation purposes using hydro chemical Studies in Malwa Region, South-western Part of Punjab, India. Appl Water Sci.7.3301-3316.

Kelly, W.P.1940. Permissible composition and concentration of Irrigation water. Proceedings of the American Society of Civil Engineers.66.607-613.

Meybeck,M., Kuusisto, E., Makela, A. \& Malkki, E.1996. Water Quality Monitoring- A Practical Guide to the Design and Implementation of Freshwater Quality Studies and Monitoring Programmes. United Nations Environment Programme and The World Health Organisation.

Meena, Arjun Lal \& Bisht, Priyanka. 2020. Study of Fluoride Contamination in Water of Chaksu tehsil, Jaipur, Rajasthan, India. Journal of Xi'an University of Architecture \& Technology. Volume XII, Issue II. pp:1562-1569.

Meena, Arjun Lal \& Bisht, Priyanka.2020.Assessment of Quality of Potable water in Bassi Tehsil, Jaipur District, Rajasthan, India. Our Heritage. Vol-68-Issue-30. pp.:85938607.

Pick, Tom. 2011. Assessing Water Quality for Human Consumption, Agriculture and Aquatic Life Uses. United States Department of Agriculture. Natural Resources Conservation Service. Environment Technical Note. MT-1 (Rev.2).pp:17.

Richards, L.A.1954. Diagnosis and Improvement of Saline and Alkali Soils. United States Department of Agriculture.60.

Rawat, Kishan R., Singh, Sudhir Kumar. \& Gautam, Sandeep Kumar.2018. Assessment of groundwater quality for irrigation use: a peninsular case study. Applied Water Science.8.233.

Wilcox.L.Y.1955. Classification and Use of Irrigation Water. United States Department of Agriculture.969

Xu, Panpan., Feng, Wenwen., Qian, Hui \& Zhang, Qiying.2019.Hydrogeochemical Characterization and Irrigation Quality Assessment of Shallow Groundwater in the Central-Western Guanzhong Basin, China. International Journal of Environmental Research and Public Health.16.1492.

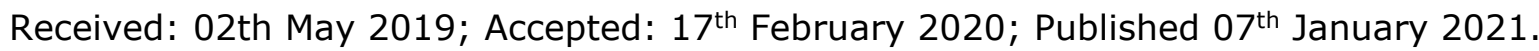

